\title{
Research
}

\section{Relationship between prescribing of antibiotics and other medicines in primary care:}

a cross-sectional study

\begin{abstract}
\section{Background}

High levels of antibiotic prescribing are a major concern as they drive antimicrobial resistance. It is currently unknown whether practices that prescribe higher levels of antibiotics also prescribe more medicines in general.
\end{abstract}

Aim

To evaluate the relationship between antibiotic and general prescribing levels in primary care.

\section{Design and setting}

Cross-sectional study in 2014-2015 of 6517 general practices in England using NHS digital practice prescribing data (NHS-DPPD) for the main study, and of 587 general practices in the UK using the Clinical Practice Research Datalink for a replication study.

\section{Method}

Linear regression to assess determinants of antibiotic prescribing

\section{Results}

NHS-DPPD practices prescribed an average of 576.1 antibiotics per 1000 patients per year (329.9 at the 5th percentile and 808.7 at the 95th percentile). The levels of prescribing of antibiotics and other medicines were strongly correlated. Practices with high levels of prescribing of other medicines la rate of 27159.8 at the 95th percentile) prescribed $80 \%$ more antibiotics than low-prescribing practices (rate of 8815.9 at the 5 th percentile). After adjustment, NHS-DPPD practices with high prescribing of other medicines gave $60 \%$ more antibiotic prescriptions than lowprescribing practices /corresponding to higher prescribing of 276.3 antibiotics per 1000 patients per year). Prescribing of non-opioid painkillers and benzodiazepines were also strong indicators of the level of antibiotic prescribing. General prescribing levels were a much stronger driver for antibiotic prescribing than other risk factors, such as deprivation.

\section{Conclusion}

The propensity of GPs to prescribe medications generally is an important driver for antibiotic prescribing. Interventions that aim to optimise antibiotic prescribing will need to target general prescribing behaviours, in addition to specifically targeting antibiotics.

\section{Keywords}

antibiotics; benzodiazepines; drug prescribing; general practice; non-antibiotics; non-opioid painkillers.

\section{INTRODUCTION}

Antibiotic overprescribing is a major concern as it increases antimicrobial resistance and reduces antibiotic effectiveness. Antimicrobial resistance makes common infections harder to treat. The UK government has announced an ambition to reduce inappropriate antibiotic prescribing by $50 \%$ by $2020 .^{2}$ Nearly three-quarters of antibiotics prescribed in England are in primary care. ${ }^{3,4}$ There have been multiple interventions and initiatives to reduce antibiotic prescribing in primary care, including guidelines, education, audit tools, public education campaigns, and local antimicrobial stewardship activities. ${ }^{5,6}$ Many of these initiatives have focused specifically on improving the choice of treatment or understanding of common infections, rather than on system-level interventions, such as the organisation of general practices. A recent intervention was based on behavioural insights and provided feedback to clinicians of their prescribing behaviours compared with their peers.? Although there has been a reduction in antibiotic prescribing in general practice, significantly more work is required to

Y Li, MSc, PhD student; $\mathbf{A}$ Mölter, MSc, PhD, research associate; V Palin, MRes, PhD, researcher; M Belmonte, MSc, PhD, research associate; M Sperrin. PhD, MMORSE, CStat CSci, FHEA, senior lecturer, Health e-Research Centre, School of Health Sciences, Faculty of Biology, Medicine and Health, University of Manchester, Manchester, UK. DM Ashcroft MSc, PhD, FRPharmS, professor and researcher, Centre for Pharmacoepidemiology and Drug Safety, and NIHR Greater Manchester Patient Safety Translational Research Centre, School of Health Sciences, Faculty of Biology, Medicine and Health, University of Manchester, Manchester, UK A White, BSc (Hons), director of Clinical Services and pharmacist, NHS Greater Manchester Shared Service, Oldham, UK. W Welfare, MPH, MRCP, $\mathrm{FFPH}$, consultant in health protection and interim head of health protection, Public Health England North West, Manchester, UK. TP van Staa, MA, meet the government's antibiotic-reducing ambition. The objective of this study was to evaluate the characteristics of practices that prescribe a greater number of antibiotics, and examine their prescribing of other medicines.

\section{METHOD}

The authors used NHS digital practice prescribing data (NHS-DPPD) for the main study, and the Clinical Practice Research Datalink (CPRD) for the replication study. The rationale for using both datasets was to independently replicate the findings and evaluate the robustness of results, adjusting for different risk factors. The importance of replication of research has been advocated in literature. ${ }^{8}$ The reason for using NHS-DPPD in the main study is that it contains practice-level data from almost all practices in England. CPRD was used in the replication because it contains anonymised patient-level clinical data providing different risk factors from NHSDPPD. ${ }^{9}$ NHS-DPPD contains the summary counts of prescriptions in a practice issued by GPs and other healthcare staff (such as nurses), practice name and postcode, and

MSc, PhD, MD, professor and researcher, Health e-Research Centre, School of Health Sciences, Faculty of Biology, Medicine and Health, University of Manchester, Manchester, UK, and Utrecht Institute for Pharmaceutical Sciences, Utrecht University, Utrecht, Netherlands.

Address for correspondence

Tjeerd van Staa, Health e-Research Centre, School of Health Sciences, Faculty of Biology, Medicine and Health, University of Manchester, Oxford Road, Manchester M13 9PL, UK

Email: tjeerd.vanstaadmanchester.ac.uk Submitted: 11 May 2018; Editor's response: 22 June 2018; final acceptance: 13 July 2018 ()British Journal of General Practice

This is the full-length article (published online 18 Dec 2018) of an abridged version published in print. Cite this version as: $\mathbf{B r} \mathbf{J}$ Gen Pract 2018; DOI: https://doi.org/10.3399/bjgp18X700457 


\section{How this fits in}

Current interventions that focus specifically on improving the treatment or understanding of common infections have had limited effectiveness in reducing antibiotic prescribing in primary care. The propensity of GPs to prescribe medications is an important driver for antibiotic prescribing. Interventions that aim to optimise antibiotic prescribing will need to consider the general prescribing behaviour in primary care.

number of registered patients (list size). The authors' analyses were based on the NHS-DPPD data from 2015. ${ }^{10}$ Medication groups were analysed based on the British National Formulary (BNF). NHS-DPPD was linked using the practice postcode or practice ID to the Index of Multiple Deprivation (IMD), ${ }^{11}$ patient survey data of experiences of their practice, ${ }^{12}$ Quality and Outcomes Framework (QOF) data for chronic obstructive pulmonary disease (COPD) and asthma, ${ }^{9}$ and GP workforce data. ${ }^{13}$ The QOF is a national incentive programme that provides financial rewards to GP practices in England for the quality of care. ${ }^{14}$

CPRD contains anonymised patient-level electronic health records (EHRs) of a broadly representative sample of general practices in the UK, and includes $>10$ million patients. ${ }^{9}$ The data recorded in the CPRD include patient demographic information,

Table 1. Baseline characteristics of NHS-DPPD and CPRD practices

\begin{tabular}{lcc} 
Baseline characteristics of practices & $\begin{array}{c}\text { NHS-DPPD } \\
\text { ( } \mathbf{n}=\mathbf{6 5 1 7 )}\end{array}$ & $\begin{array}{c}\text { CPRD } \\
\text { ( } \boldsymbol{n}=\mathbf{5 8 7 7}\end{array}$ \\
\hline List per full-time equivalent GP, mean (SD) & $2306.2(12114.0)$ & $\mathrm{n} / \mathrm{a}^{\mathrm{a}}$ \\
\hline Percentage of patients in London & 5.7 & 12.8 \\
\hline Percentage of patients in North of England & 49.7 & 54.3 \\
\hline Percentage of patients in South of England & 44.6 & 32.9 \\
\hline Practice list size, mean (SD) & $7558.0(4194.8)$ & $7732.2(3516.3)$ \\
\hline Index of Multiple Deprivation 2015 score, mean (SD) & $25.9(17.4)$ & $\mathrm{n} / \mathrm{a}^{\mathrm{a}}$ \\
\hline Adult skills sub-domain deprivation score, mean (SD) & $0.3(0.1)$ & $\mathrm{n} / \mathrm{a}^{\mathrm{a}}$ \\
\hline Health deprivation and disability score, mean (SD) & $0.2(0.9)$ & $\mathrm{n} / \mathrm{a}^{\mathrm{a}}$ \\
\hline Percentage of female patients, mean (SD) & $50.0(2.2)$ & $58.1(2.1)$ \\
\hline Rate of prescribing of other medicines, mean (SD) & $17631.3(5707.8)$ & $16587.3(5923.6)$ \\
\hline Rate of prescribing of antibiotics, mean (SD) & $576.1(148.1)$ & $578.9(177.4)$ \\
\hline Rate of prescribing of non-opioid painkillers, mean (SD) & $1211.4(544.4)$ & $1365.7(611.3)$ \\
\hline Rate of prescribing of benzodiazepines, mean (SD) ${ }^{\mathrm{b}}$ & $274.8(162.4)$ & $325.1(247.1)$ \\
\hline
\end{tabular}

${ }^{a} \mathrm{n} / \mathrm{a}$ means the dataset does not have the variable. ${ }^{b}$ Rate per 1000 patients per year. $C P R D=$ Clinical Practice Research Datalink. $D P P D=$ digital practice prescribing data. $n / a=$ not applicable. $S D=$ standard deviation . prescriptions supplied lincluding BNF categoryl, diagnoses, test results, and specialist referrals. The postcodes of CPRD practices were not available to researchers (for reasons of data confidentiality). CPRD data for 2014 were used, as this was the most recent calendar year available to the authors.

General practices with outlier values were excluded from the analyses. Specifically, practices with a small list size $(\leq 750)$, few number of patients per GP full-time equivalent $(\leq 500)$, and practices that were below the 1st and above the 99th percentile for the rate of antibiotic prescriptions ${ }^{15}$ were excluded. Practices with a small number of patients per GP full-time equivalent were retained for CPRD as this dataset did not have the GP full-time equivalent variable. Practices that had missing values in one of the covariates were also excluded (the percentage of missing records was small, ranging from $0.5 \%$ to $1.3 \%$ ).

The variables of interests included the rate of antibiotic prescribing and that of other (non-antibiotic) medicines. The authors further explored the associations with non-opioid analgesics and benzodiazepine prescribing, as longstanding guidance has also advocated judicious use of these medicines. The rates were the sum of prescriptions in each practice divided by list size. The selection of medicines was based on the BNF classification Isystemic antibiotics BNF categories 5.1.1 to 5.1.8, and 5.1.11 to 5.1.13), other medicines 11-14 excluding 1.8, 11.9 and 13.11, 13.12 and 13.13, and systemic antibiotics), non-opioid analgesics (4.7.1 to 4.7.5), and benzodiazepines (4.1.1 and 4.1.2). Prescriptions for bandages or devices were excluded.

Potential confounders between the rates of antibiotic prescribing and risk factors in the NHS-DPPD analyses were deprivation scores in the following domains: employment; health; crime; income deprivation affecting older people, children, and young people's education; adult skills; wider barriers; indoor environments; outdoor environments; practice characteristics (such as patient's age, or QOF achievements); and patient survey results of satisfaction with their practice. Postcodes were used to define the regional location of the practices. ${ }^{16}$ Potential confounders in the CPRD analyses included distribution of Charlson comorbidity index, ${ }^{17}$ smoking and body mass index, rates of patients consulting their practice for upper respiratory tract infections, lower respiratory tract infection, or urinary tract 


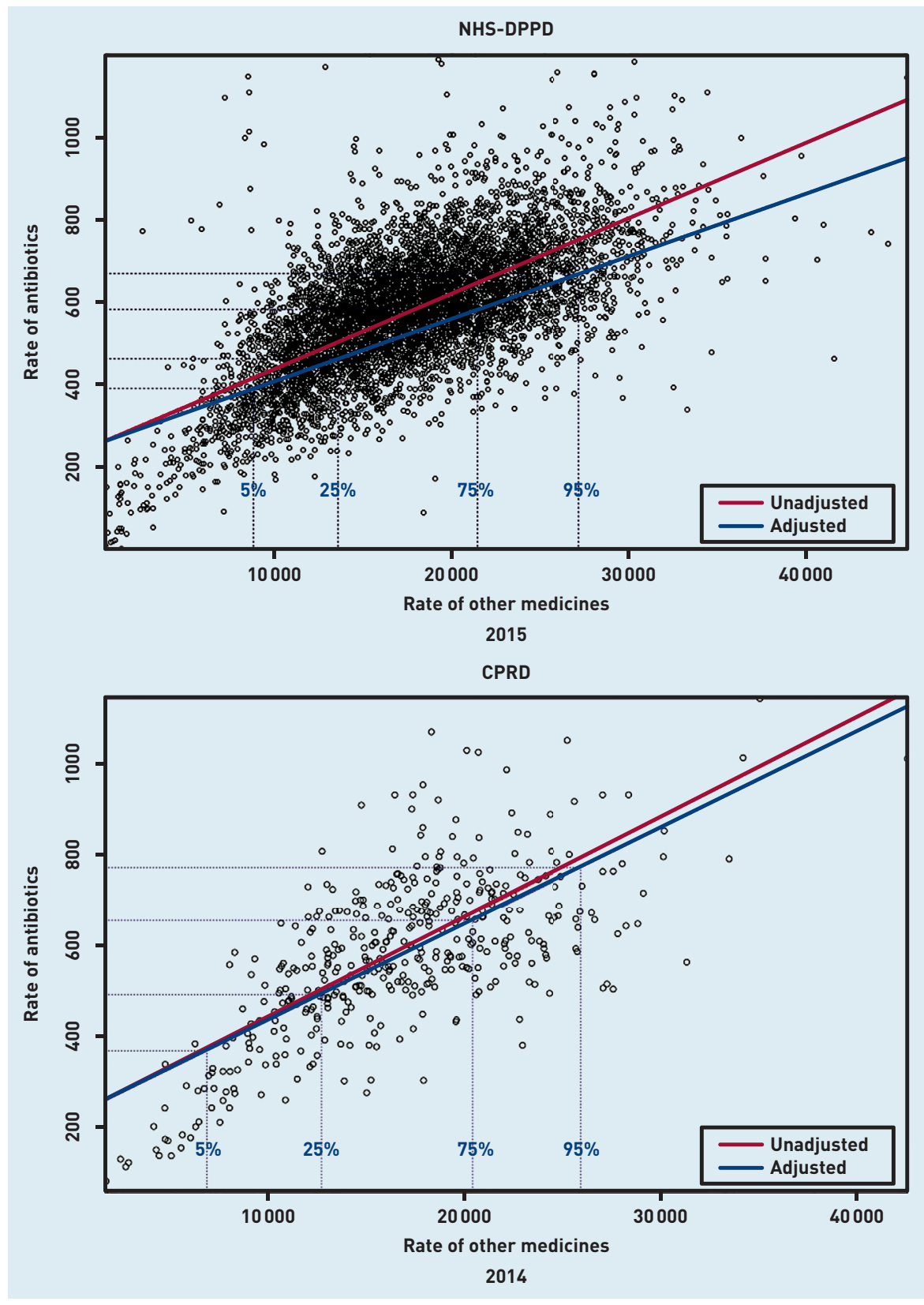

Figure 1. Associations between rates of prescribing of antibiotics and other medicines in general practices. $C P R D=$ Clinical Practice Research Datalink. $D P P D=$ digital practice prescribing data. infection, lung or skin infection, ethnicity, and region of practice.

Linear regression measured the association between rates of antibiotics prescribing (dependent variable) and risk factors (independent variable), such as rate of prescribing of other medicines. The interquartile range (IQR) and 5th and 95th percentiles were measured in the distribution of each risk factor. The authors quantified the change in the rate of antibiotic prescribing by multiplying risk factors' coefficients (beta) from linear models to corresponding risk factors IQR lor range of 5th percentile to 95th percentile). This common approach is similar to standardised coefficients, as both of them are a way to present models coefficients (betas) of all risk factors in the same scale, so the coefficients of all risk factors can be fairly compared with each other. The list size of practices was used as a weight. Standard techniques were used to reduce the number of potential confounders in the adjusted models lincluding exclusion of variables of Pearson correlation coefficients of $>0.6$, those that influenced the variance inflation factor $\geq 10$ reflecting severe collinearity between variables, and backward regression using Akaike information criterion). Residual, normal $Q-Q$, standardised residual, and Cook's distance plots were used to check the statistical assumptions of the regression models. Poisson models were also fitted to check whether their results were consistent with the linear regression models. Pearson coefficients between rates of antibiotic prescribing and those of other medicines, painkillers, and benzodiazepines were calculated.

An explorative analysis evaluated the association between the rate of antibiotic prescribing and that of other specific classes of medicines. These classes included all BNF categories for medicines lexcluding non-opioid analgesics and benzodiazepines) prescribed to at least $1 \%$ of the study population. The false discovery rate adjusted $P$-values were estimated in order to minimise the effects of multiple testing and the finding of false-positive statistical associations. ${ }^{18}$

\section{RESULTS}

Table 1 shows the practice characteristics of the NHS-DPPD and CPRD practices. There were 28 million antibiotic prescriptions and 840 million other medicines recorded in NHSDPPD. Figure 1 shows the rates of antibiotic and other prescribing in NHS-DPPD and CPRD practices leach circle representing a practice). The adjusted regression model of prescription of other medicines and other determinants explained $56 \%$ of the variation of antibiotic prescription in NHS-DPPD $162.9 \%$ in CPRD). When removing the prescribing rate of other medicines from the model, this variation reduced to $40.7 \%$. Analysis of variance (Anova) model comparison showed that the model with the prescribing rate of other medicines was a statistically better model than the model without. Practices with higher levels of prescribing of other medicines also issued considerably more antibiotics. Pearson coefficients between prescribing of antibiotics and other medicines was 0.65 in NHS-DPPD (0.70 in CPRD), between 


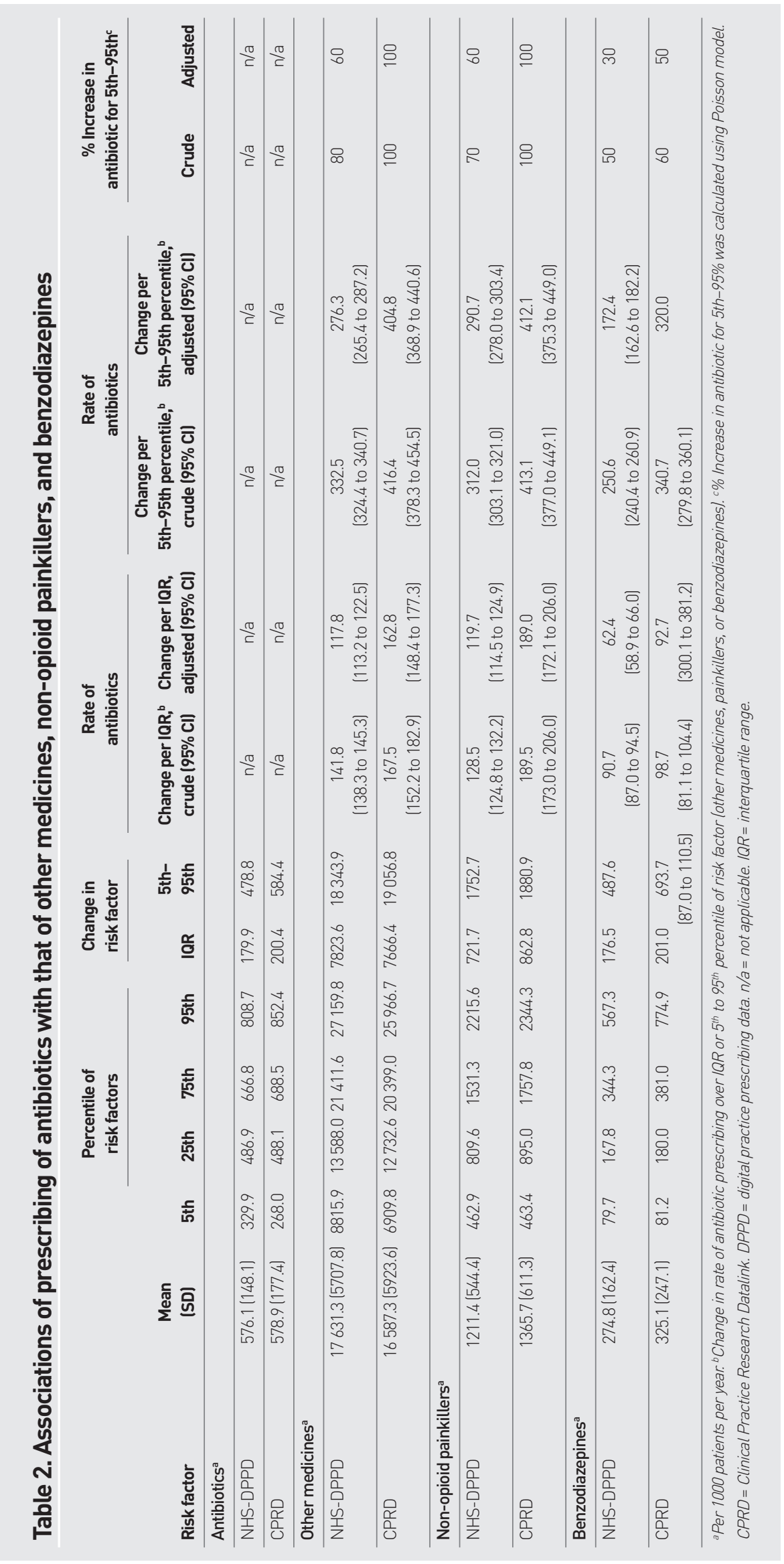


Figure 2. Associations between rates of prescribing of antibiotics and non-opioid painkillers in general practices.

$C P R D=$ Clinical Practice Research Datalink. $D P P D=$ digital practice prescribing data.
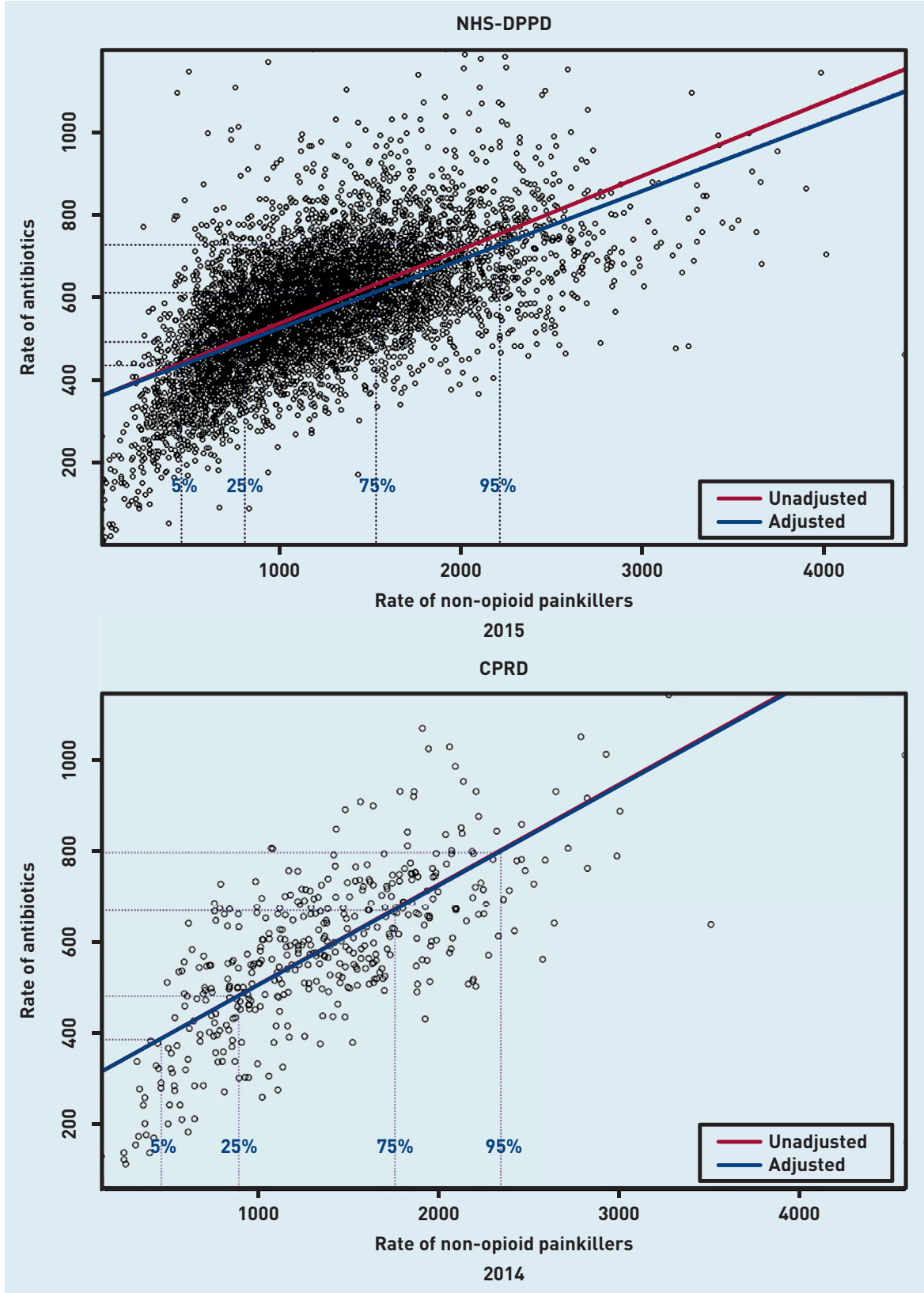

antibiotics and non-opioid analgesics 0.61 in NHS-DPPD (0.72 in CPRD), and between antibiotics and benzodiazepines 0.47 in NHSDPPD (0.60 in CPRD).

Table 2 displays the associations between prescribing of antibiotics and other medicines, benzodiazepines, and non-opioid analgesics. NHS-DPPD practices prescribed, on average, 576.1 antibiotics per 1000 patients per year. There was marked variation in the rate of antibiotic prescribing across NHS-DPPD practices, ranging from a rate of 329.9 in the 5 th percentile to 808.7 in the 95th percentile. There was also strong variability in the prescribing of other medicines across practices (rate of 8815.9 in 5th and 27159.8 in 95th percentiles). As shown in Table 2 , the rate of antibiotic prescribing of highprescribing practices was $80 \%$ and, after statistical adjustment, 60\% higher than lowprescribing practices. Similar results were found in CPRD practices.

The prescribing of non-opioid analgesics (Figure 2) and benzodiazepines (Figure 3) was also strongly correlated with that of antibiotics. The adjusted regression model of prescription of painkillers and other determinants explained $53.2 \% \quad(55.1 \%$ in CPRD) of the variation of antibiotic prescription in NHS-DPPD. NHS-DPPD practices with high levels of prescribing of non-opioid analgesics (95th percentile) 
Figure 3. Associations between rates of prescribing of antibiotics and benzodiazepines in general practices. $C P R D=$ Clinical Practice Research Datalink $D P P D=$ digital practice prescribing data

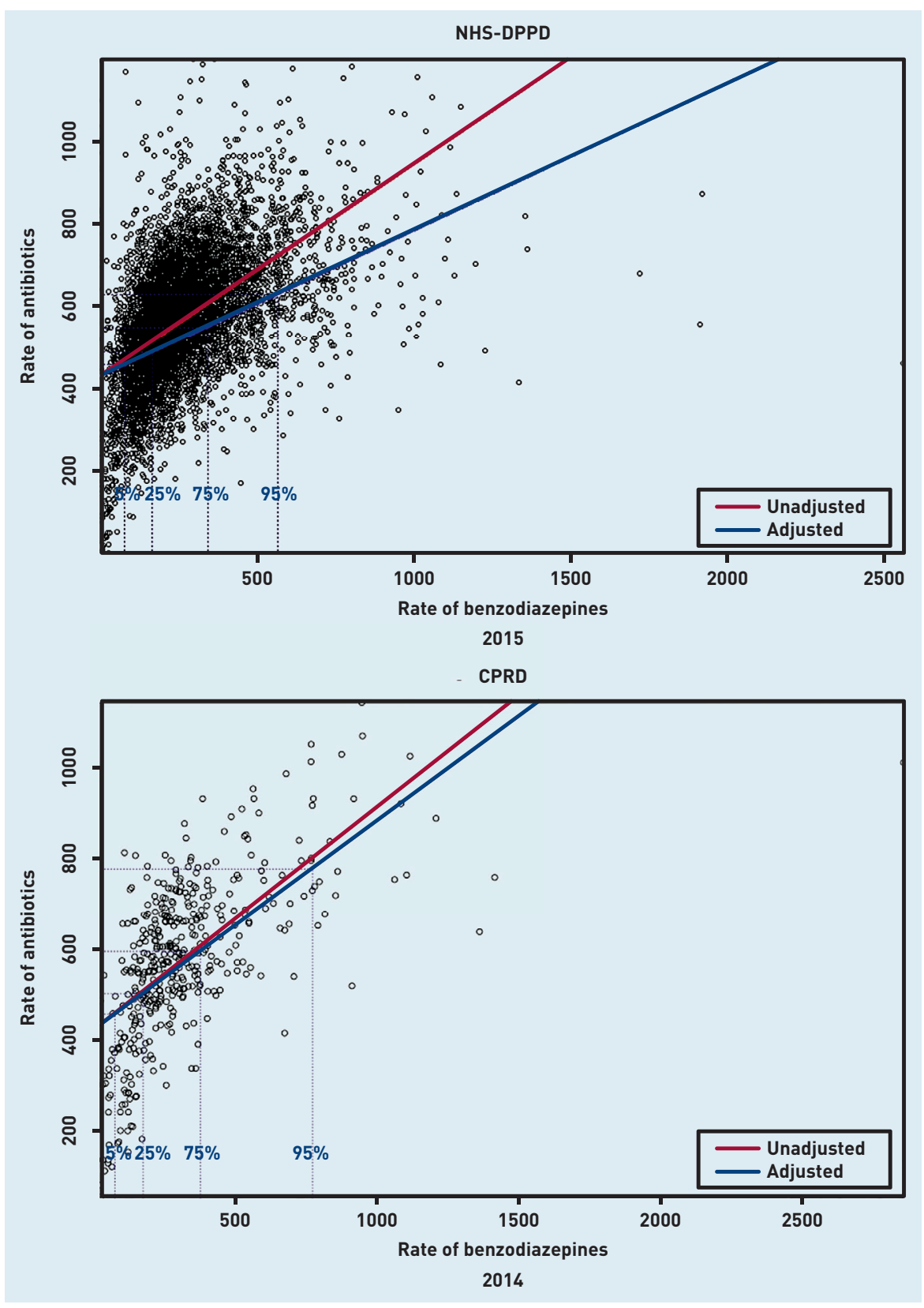

gave $70 \%$ and, after statistical adjustment 60\% more antibiotics compared with lowprescribing practices (5th percentile). The adjusted regression model of prescription of benzodiazepines and other determinants explained $49.6 \%$ (46.4\% in CPRD) of the variation of antibiotic prescription in NHS DPPD. Benzodiazepine prescribing was also strongly related to antibiotic prescribing with, respectively, 50\% and, after statistical adjustment, 30\% higher antibiotic prescribing between low- and high-prescribing NHSDPPD practices.

When increasing only one risk factor from the 5th to the 95th percentile and holding all other risk factors constant, the rate of prescribing for other medicines was associated with the biggest change of antibiotic prescribing in NHS-DPPD (276.3, $95 \% \mathrm{Cl}=265.4$ to 287.2 ) compared with other risk factors, including indicators of socioeconomic status (Table 3 ).

Table 4 presents the result of the explorative analyses of BNF classes that had the most significant associations (those with the smallest $P$-values) with antibiotic prescribing. It was found that prescribing of proton pump inhibitors and that of antibiotics was significantly associated. Other significantly correlated medication classes included oral glucocorticoids and selective serotonin reuptake inhibitors. 

Table 3. Analysis of relative importance of continuous risk factors for
antibiotic prescribing

\begin{tabular}{|c|c|}
\hline Risk factors & $\begin{array}{l}\text { Change in rate of } \\
\text { antibiotics }(95 \% \mathrm{CI})^{\mathrm{a}} \\
\text { over } 5 \text { th to } 95 \text { th } \\
\text { percentiles in risk factor }\end{array}$ \\
\hline & NHS-DPPD \\
\hline Rate of prescribing of other medicines & 276.3 (265.4 to 287.2 ) \\
\hline Adult skills sub-domain score in practice area & 74.2 (57.8 to 90.5$)$ \\
\hline$\%$ Male patients aged $0-4$ years in practice & 48.5 (32.4 to 64.6$)$ \\
\hline$\%$ Female patients aged $80-85$ years in practice & $41.2(29.4$ to 52.9$)$ \\
\hline Practice score in overall experience of making an appointment: not good & 28.7 (14.0 to 43.4 ) \\
\hline Health deprivation and disability score in practice area & $23.5(5.3$ to 41.8$)$ \\
\hline$\%$ Male patients aged $5-9$ years in practice & $25.0(9.0$ to 40.9$)$ \\
\hline$\%$ Patients in practice with arthritis or long-term joint problem & 20.3 (9.1 to 31.5) \\
\hline$\%$ Female patients aged $45-49$ years in practice & $21.5(9.6$ to 33.5$)$ \\
\hline Crime score in practice area & 16.0 (3.8 to 28.2 ) \\
\hline$\%$ Male patients aged $55-59$ years in practice & $16.9(2.5$ to 31.2$)$ \\
\hline Medical conditions - \% none of these conditions & $13.9(1.1$ to 26.6$)$ \\
\hline$\%$ Patients in practice with another long-term condition & $11.5(2.5$ to 20.6$)$ \\
\hline QOF asthma achievement, \% & $-5.8(-10.6$ to -1.0$)$ \\
\hline Practice score in rating of GP involving patients in decisions about care: \% good & $-12.8(-21.2$ to -4.3$)$ \\
\hline Indoors sub-domain score in practice area & $-13.4(-22.2$ to -4.5$)$ \\
\hline Outdoors sub-domain score in practice area & $-16.2(-28.6$ to -3.9$)$ \\
\hline Practice score in last seen or spoke to a GP: over the past 3 months & $-17.3(-26.0$ to -8.6$)$ \\
\hline Practice score in confidence and trust in GP: \% no, not at all & $-22.2(-32.8$ to -11.6$)$ \\
\hline$\%$ Male patients aged $40-44$ years in practice & $-25.1(-35.8$ to -14.4$)$ \\
\hline Practice score of last time wanted to see GP or nurse: not seen GP at surgery & $-23.3(-31.5$ to -15.0$)$ \\
\hline Practice score of overall experience of GP surgery: not good & $-24.9(-41.1$ to -8.7$)$ \\
\hline Income deprivation score in practice area affecting older people & $-42.5(-58.6$ to -26.4$)$ \\
\hline Employment score in practice area & $-51.5(-71.3$ to -31.8$)$ \\
\hline & CPRD \\
\hline Rate of prescribing of other medicines & 404.8 (368.9 to 440.6$)$ \\
\hline Rate of consultations for upper respiratory tract infections & 43.8 (9.3 to 78.3$)$ \\
\hline$\%$ Patients in practice who are smokers & $-41.9(-79.3$ to -4.5$)$ \\
\hline Duration of GP visit, mean & $-60.9(-95.9$ to -25.8$)$ \\
\hline \% Patients in practice with higher Charlson comorbidity index & $-71.7(-108.3$ to -35.2$)$ \\
\hline \multicolumn{2}{|c|}{$\begin{array}{l}{ }^{a} \text { Per } 1000 \text { patients per year. }{ }^{b} \text { Change in rate of antibiotic prescribing comparing practices in lower }\left(5^{\text {th }}\right) \text { with higher } \\
\text { percentiles }\left(95^{\text {th }}\right) \text { of the risk factor. CPRD = Clinical Practice Research Datalink. DPPD = digital practice prescribing } \\
\text { data. QOF = Quality and Outcomes Framework. }\end{array}$} \\
\hline
\end{tabular}

\section{DISCUSSION}

\section{Summary}

The authors found an association between the prescribing at practice level of antibiotics and that of other medicines, non-opioid analgesics, and benzodiazepines. The rate of prescribing of other medicines was comparatively a more important risk factor for antibiotic prescribing than any other risk factors included in this study, such as deprivation. Explorative analyses also found that prescribing of proton pump inhibitors was also correlated with antibiotic prescribing.

In conclusion, the propensity of GPs to prescribe medications generally is an important driver for antibiotic prescribing. Interventions that aim to optimise antibiotic prescribing will need to consider general prescribing behaviours of GPs.

\section{Strengths and limitations}

This study has several limitations. One 


\begin{tabular}{|c|c|c|}
\hline \multirow[b]{2}{*}{$\begin{array}{l}\text { Risk factor - type of medicines } \\
\text { (BNF category) }\end{array}$} & \multicolumn{2}{|c|}{$\begin{array}{l}\text { Change in rate of antibiotics }\left(95 \% \mathrm{Cl}^{\mathrm{b}}\right. \\
\text { over } 5 \text { th to } 95 \text { th percentiles in risk factor }\end{array}$} \\
\hline & $\begin{array}{l}\text { NHS-DPPD, } \\
\text { crude }(95 \% \mathrm{Cl})\end{array}$ & $\begin{array}{c}\text { CPRD, } \\
\text { crude }(95 \% \mathrm{Cl})\end{array}$ \\
\hline Proton pump inhibitors (1.3.5) & 316.0 (307.5 to 324.5 ) & 406.1 (365.4 to 446.8) \\
\hline Renin-angiotensin system drugs (2.5.5) & 287.1 (277.7 to 296.5) & 312.7 (263.2 to 362.3$)$ \\
\hline Antiplatelet drugs (2.9) & $283.2(273.9$ to 292.6$)$ & $346.4(300.1$ to 392.7$)$ \\
\hline Drugs used in nausea and vertigo (4.6) & 335.6 (326.7 to 344.5$)$ & 258.9 (220.8 to 297.0$)$ \\
\hline Selective serotonin reuptake inhibitors (4.3.3) & 332.6 (323.7 to 341.4) & $402.7(363.2$ to 442.2$)$ \\
\hline Corticosteroids (respiratory) (3.2) & 323.4 (314.3 to 332.5 ) & $263.2(214.4$ to 311.9$)$ \\
\hline Antispasmodic and other drugs altering gut motility (1.2) & 301.3 (291.4 to 311.2) & $299.0(253.8$ to 344.1$)$ \\
\hline Glucocorticoid therapy (6.3.2) & 322.0 (312.8 to 331.3) & $158.3(110.5$ to 206.1$)$ \\
\hline Beta-adrenoceptor blocking drugs (2.4) & 301.1 (292.1 to 310.1) & $363.0(317.5$ to 408.5$)$ \\
\hline Lipid-regulating drugs (2.12) & 287.9 (278.6 to 297.1$)$ & $189.2(138.7$ to 239.7$)$ \\
\hline \multicolumn{3}{|c|}{$\begin{array}{l}\text { 'Table shows the top } 10 \text { largest associations in NHS-DPPD, with corresponding results in CPRD. }{ }^{b} \text { Per } 1000 \text { patients } \\
\text { per year. }{ }^{\circ} \text { Change in rate of antibiotic prescribing comparing practices in lower (5th) with higher }(95 \text { th) percentiles } \\
\text { of the risk factor. BNF = British National Formulary. CPRD=Clinical Practice Research Datalink. DPPD = digital } \\
\text { practice prescribing data. IQR = interquartile range. }\end{array}$} \\
\hline
\end{tabular}

limitation was that CPRD practices were also included in NHS-DPPD, but both analyses were done independently and included different risk factors. This was also an observation study without randomisation between different levels of prescribing, and some risk factors were not available, such as non-Western migrant status and sociocultural-determined expectations from patients. However, the authors did include strong risk factors of antibiotic prescribing as used in previous studies, ${ }^{15}$ such as practice location and deprivation score. The deprivation scores in NHS-DPPD analyses were based on the postcodes of practices rather than on the postcodes of patients, which may not fully represent patients' deprivation. A further limitation was that the authors did not have information on the clinical reason for prescribing in the NHS-DPPD. Higher prescribing of, for example, antiplatelet drugs might be explained by a proactive prevention-oriented approach.

\section{Comparison with existing literature}

Wang et al evaluated predictors of antibiotic prescribing in UK general practice, and reported that characteristics of general practices associated with higher antibiotic prescribing include practice location, shorter duration of GP appointments, nontraining practices, and percentage of GPs who are male, $>45$ years old, and qualified outside the UK. ${ }^{15}$ That study included only nine predictors, which explained $17.2 \%$ of the variation, ${ }^{15}$ whereas the current model explained $56 \%$ of the variation in antibiotic prescribing. A recent Danish study showed that insufficient or overuse of diagnostic tests, lower rates of phone consultations, and higher consultation rates in the practice were associated with higher rates of antibiotic prescribing. ${ }^{19}$ The current study confirms that practice characteristics are important predictors of the levels of antibiotic prescribing, and that these may be more important than other risk factors, such as socioeconomic status ${ }^{15,20,21}$ or patient characteristics. ${ }^{15}$

\section{Implications for research and practice}

Current indicators of antibiotic prescribing in general practices do not take into account practice or population characteristics. The current measure in England is STAR PU, which only takes into account the age and sex of patients in the practice to determine the number of antibiotic prescriptions. ${ }^{22}$ In this study, regression analysis was used to compare practices, taking into account age, sex, and multiple other risk factors. The authors' results indicate the need for further adjustment for patient population in these indicators to enable fair comparison between practices, and to target interventions appropriately.

The rates of antibiotic prescribing in UK general practice have fallen in recent years, but remain high. ${ }^{23}$ Several interventions 


\section{Funding}

Northern Health Science Alliance (NHSA) was awarded a grant by the Department of Health and Social Care to fund 'Health North Connected Health Cities'. NHSA awarded the University of Manchester as the Greater Manchester Connected Health City ('GMCHC') a grant to perform the allocated work.

\section{Ethical approval}

The study was approved by the independent scientific advisory committee for Clinical Practice Research Datalink (CPRD) research (protocol No 16_153R3A).

\section{Provenance}

Freely submitted; externally peer reviewed.

\section{Competing interests}

The authors have declared no competing interests.

\section{Open access}

This article is Open Access: CC BY-NC 4.0 licence (http://creativecommons.org/ licenses/by-nc/4.0/).

\section{Acknowledgements}

This study was part of Connected Health Cities, which is an NHSA-led programme. It is funded by the Department of Health and Social Care, and delivered by a consortium of academic and NHS organisations across the North of England. This study is based in part on data from the CPRD obtained under licence from the UK Medicines and Healthcare products Regulatory Agency (MHRA). The data are provided by patients and collected by the NHS as part of their care and support. The interpretation and conclusions contained in this study are those of the authors alone and not necessarily those of the MHRA, NHSA, the NHS, or the Department of Health and Social Care.

\section{Discuss this article}

Contribute and read comments about this article: bjgp.org/letters have been implemented or tested, but the effectiveness of most of these interventions has been modest, either through limited implementation or limited effect size. Most of the interventions have focused directly on antibiotic prescribing or the understanding of infections. Education of clinicians and/or patients has been found to improve antibiotic prescribing. ${ }^{24}$ One of the most widely used interventions has been public awareness campaigns of antibiotics and infections. ${ }^{25}$ Studies have shown that the public often misunderstand the differences between bacterial and viral infections. ${ }^{26}$ The evidence for long-term effectiveness of public campaigns is limited. ${ }^{27} \mathrm{~A}$ cluster trial of a behavioural intervention reported a shortterm reduction in antibiotic prescribing in high-prescribing practices after receiving a letter from the Chief Medical Officer in December 2014. ' However, it is unclear whether these effects were sustained over time. A UK-based cluster trial of a remotely installed, computer-delivered decision support tool that could be accessed during the consultation found a small effect on the rate of antibiotic prescribing. ${ }^{28}$ The current study confirms the conclusion from another study that a whole-system approach is needed to understand the factors influencing antibiotic management to improve the appropriate use of antibiotics in primary care. $^{29}$ One whole-systematic approach could involve pharmacists integrated with a practice. A recent programme in England involves pharmacists who review medication expenditure, ${ }^{30}$ hazardous prescribing to individual patients, ${ }^{31}$ and transfer of prescribing for patients referred from secondary care. ${ }^{32}$ This approach may be extended to also review the overall prescribing behaviour of practices compared with similar practices, in order to optimise the quality of prescribing in practices. Of course, the effectiveness and impact of these interventions will need to be evaluated. 


\section{REFERENCES}

1. Costelloe C, Metcalfe C, Lovering A, et al. Effect of antibiotic prescribing in primary care on antimicrobial resistance in individual patients: systematic review and meta-analysis. BMJ 2010; 340: c2096.

2. Davies SC. Reducing inappropriate prescribing of antibiotics in English primary care: evidence and outlook. J Antimicrob Chemother 2018; 73(4): 833-834.

3. Llor C, Bjerrum L. Antimicrobial resistance: risk associated with antibiotic overuse and initiatives to reduce the problem. Ther Adv Drug Saf 2014; 5(6): 229-241.

4. Public Health England. English surveillance programme for antimicrobial utilisation and resistance (ESPAUR). Report 2017. 2017. https://assets. publishing.service.gov.uk/government/uploads/system/uploads/attachment_ data/file/656611/ESPAUR_report_2017.pdf (accessed 7 Nov 2018).

5. Tonkin-Crine SK, Wang K, van Hecke O, et al. Clinician-targeted interventions to reduce antibiotic prescribing for acute respiratory infections in primary care: an overview of systematic reviews. Cochrane Database Syst Rev 2017; (6): CD012252. DOI: 10.1002/14651858.CD012252.

6. Harris AM, Hicks $L A$, Qaseem A. Appropriate antibiotic use for acute respiratory tract infection in adults: advice for high-value care from the American College of Physicians and the Centers for Disease Control and Prevention. Ann Intern Med 2016; 164(6): 425-434.

7. Hallsworth M, Chadborn T, Sallis A, et al. Provision of social norm feedback to high prescribers of antibiotics in general practice: a pragmatic national randomised controlled trial. Lancet 2016; 387(10029): 1743-1752.

8. Coiera E, Ammenwerth E, Georgiou A, Magrabi F. Does health informatics have a replication crisis? J Am Med Informatics Assoc 2018; 25(8): 963-968.

9. Herrett E, Gallagher AM, Bhaskaran K, et al. Data resource profile: clinical practice research datalink (CPRD). Int J Epidemiol 2015; 44(3): 827-836.

10. NHS Digital. GP practice prescribing presentation-level data - October 2015 2016. https://digital.nhs.uk/data-and-information/publications/statistical/ practice-level-prescribing-data/presentation-level-october-2015 laccessed 7 Nov 2018).

11. GOV.UK. English indices of deprivation 2015. https://www.gov.uk/government/ statistics/english-indices-of-deprivation-2015 (accessed 7 Nov 2018).

12. NHS England. GP patient survey. https://uww.gp-patient.co.uk/ SurveysAndReports (accessed 7 Nov 2018).

13. NHS Digital. General and Personal Medical Services, England 2005-2015, as at 30 September, provisional experimental statistics. 2015. http://digital.nhs.uk/ catalogue/PUB20503 laccessed 7 Nov 2018).

14. NHS Digital. Quality and Outcomes Framework business rules. https://digital. nhs.uk/data-and-information/data-collections-and-data-sets/data-collections/ quality-and-outcomes-framework-qof\#quality-and-outcome-frameworkbusiness-rules (accessed 7 Nov 2018).

15. Wang KY, Seed $P$, Schofield $P$, et al. Which practices are high antibiotic prescribers? A cross-sectional analysis. Br J Gen Pract 2009; DOI: https://doi. org/10.3399/bjgp09X472593
16. Hacking JM, Muller S, Buchan IE. Trends in mortality from 1965 to 2008 across the English north-south divide: comparative observational study. BMJ 2011; 342: d508.

17. Sundararajan V, Henderson T, Perry C, et al. New ICD-10 version of the Charlson comorbidity index predicted in-hospital mortality. J Clin Epidemiol 2004; 57(12): 1288-1294.

18. Goldman M. Why is multiple testing a problem?2008. https://www.stat.berkeley. edu/ mgoldman/Section0402.pdf (accessed 7 Nov 2018).

19. Aabenhus R, Siersma V, Sandholdt H, et al. Identifying practice-related factors for high-volume prescribers of antibiotics in Danish general practice. $J$ Antimicrob Chemother 2017; 72(8): 2385-2391.

20. Cowey JR, Johnson BF, Elliott V, et al. An association between socioeconomic deprivation and primary care antibiotic prescribing in Scotland. J Antimicrob Chemother 2014; 69(3): 835-841.

21. Steinke DT, Bain DJ, MacDonald TM, Davey PG. Practice factors that influence antibiotic prescribing in general practice in Tayside. J Antimicrob Chemother 2000; 46(3): 509-512.

22. NHS Digital. Prescribing measures, indicators and comparators. NHSD, 2014. http://content.digital.nhs.uk/prescribing/measures laccessed 7 Nov 2018).

23. Gulliford MC, Dregan A, Moore MV, et al. Continued high rates of antibiotic prescribing to adults with respiratory tract infection: survey of 568 UK general practices. BMJ Open 2014; 4(10): e006245.

24. Ohl CA, Luther VP. Health care provider education as a tool to enhance antibiotic stewardship practices. Infect Dis Clin North Am 2014; 28(2): 177-193.

25. Norris P, Chamberlain K, Dew K, et al. Public beliefs about antibiotics, infection and resistance: a qualitative study. Antibiot (Basel) 2013; 2(4): 465-476.

26. Diamond J, McQuillan J, Spiegel AN, et al. Viruses, vaccines and the public. Mus Soc Issues 2016; 11(1): 9-16.

27. Saam M, Huttner B, Harbarth S. WHO Collaborating Centre on Patient Safety. Evaluation of antibiotic awareness campaigns. 2017. http://www.who. int/selection_medicines/committees/expert/21/applications/s6_antibiotic_ awareness_campaigns.pdf (accessed 7 Nov 2018).

28. Gulliford MC, van Staa T, Dregan A, et al. Electronic health records for intervention research: a cluster randomized trial to reduce antibiotic prescribing in primary care (eCRT Study). Ann Fam Med 2014; 12(4): 344-351.

29. Charani E, Cooke J, Holmes A. Antibiotic stewardship programmes - what's missing? J Antimicrob Chemother 2010; 65(11): 2275-2277.

30. Bush J, Langley CA, Jenkins D, et al. Clinical pharmacists in general practice: an initial evaluation of activity in one English primary care organisation. Int J Pharm Pract 2017; https://doi.org/10.1111/ijpp.12426.

31. Avery AJ. Pharmacists working in general practice: can they help tackle the current workload crisis? Br J Gen Pract 2017; DOI: https://doi.org/10.3399/ bjgp17X692201.

32. Komwong D, Greenfield G, Zaman H, et al. Clinical pharmacists in primary care: a safe solution to the workforce crisis? J Royal Soc Med 2018; 111(4): 120-124. 